\title{
The Role for Tocilizumab in COVID-19 Patients: Reflections on Monza Cohort Data
}

This article was published in the following Dove Press journal:

Infection and Drug Resistance

\author{
Serena Capici ${ }^{1} *$ \\ Luca Sala ${ }^{1, *}$ \\ Stefania Galimberti ${ }^{2}$ \\ Maria Grazia Valsecchi ${ }^{2}$ \\ Nicola Squillace iD ${ }^{3}$ \\ Giulia Gustinetti ${ }^{3}$ \\ Marina Elena Cazzaniga (D) ${ }^{1,4}$ \\ Paolo Bonfanti id ${ }^{3,4}$ \\ 'Phase I Research Unit, ASST Monza, \\ Monza, Italy; ${ }^{2}$ Bicocca Bioinformatics \\ Biostatistics and Bioimaging B4 Center, \\ School of Medicine and Surgery, \\ University of Milano - Bicocca, Monza, \\ Italy; ${ }^{3}$ Infectious Disease Unit, ASST \\ Monza, Monza, Italy; ${ }^{4}$ School of Medicine \\ and Surgery, University of Milano- \\ Bicocca, Monza, Italy \\ *These authors contributed equally to \\ this work
}

\begin{abstract}
The severe acute respiratory syndrome coronavirus 2 pandemic has dominated the global health scenario from the beginning of 2020 and still represents a major health emergency. Cytokine inhibitors as tocilizumab have been used to treat COVID-19 severe pneumonia with conflicting results. We performed a retrospective study whose results can contribute to the general overview regarding the role of these agents in severe COVID-19 pneumonia, suggesting an interesting, even not statistically significant evidence of the effectiveness of tocilizumab treatment in this disease and sow a seed of reflection about their use in future waves of pandemic. We compared two cohorts of patients treated with local standard of care and with tocilizumab in the experimental one. With a median followup of 92 days, deaths were 6 and 16 in the tocilizumab and the standard of care group, respectively. With a longer follow-up than previous studies, a trend in difference with regards to mortality of the groups was observed.
\end{abstract}

Keywords: Sars-Cov-2, COVID-19, pneumonia, tocilizumab

\section{Introduction}

From the beginning of 2020 global health scenario has been dominated by the severe acute respiratory syndrome coronavirus 2 (Sars-Cov-2) pandemic and there is still an urgent need for an effective treatment, especially for the severe coronavirus disease 2019 (COVID-19) pneumonia. ${ }^{1}$ Since the most critical patients can develop a cytokine storm syndrome, selective cytokine inhibitors as tocilizumab have been used to treat COVID-19 severe pneumonia. ${ }^{2,3}$ So far mainly monocentric retrospective studies on few patients have been published using different endpoints on short follow-up and showing conflicting results. ${ }^{4-6}$ A recent review by Cortegiani and colleagues confirmed the lack of evidence supporting the clinical use of tocilizumab. ${ }^{7}$ Preliminary data coming from a randomized, double-blind, placebo-controlled Phase III trial investigating tocilizumab in patients with COVID-19 pneumonia are not encouraging but, in our opinion, the inclusion criteria of the study were too broad to explore the correct target of patients who might benefit from this drug (https:/www.roche.com/investors/updates/inv-update2020-07-29.htm).

On the other hand, data coming from EMPACTA and BACC trials, ${ }^{8,9}$ two randomized, double-blind, placebo-controlled phase III trials, are not conclusive to support tocilizumab administration in patients without high-flow oxygen.
Correspondence: Marina Elena Cazzaniga Phase I Research Unit, ASST Monza, Monza, Italy

Tel +390392339037

Email marina.cazzaniga@asst-monza.it
Infection and Drug Resistance 202 I:|4 |389-1392

1389

DovePress if in $>$

(c) (i) (5) 2021 Capici et al. This work is published and licensed by Dove Medical Press Limited. The full terms of this license are available at https://www.dovepress.com/terms.

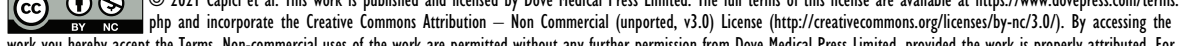
work you hereby accept the Terms. Non-commercial uses of the work are permitted without any further permission from Dove Medical Press Limited, provided the work is properly attributed. For permission for commercial use of this work, please see paragraphs 4.2 and 5 of our Terms (https://www.dovepress.com/terms.php). 


\section{Patients and Methods}

At San Gerardo Hospital, ASST-Monza, Italy, we analyzed in a retrospective study patients with severe COVID-19 pneumonia who were receiving high-flow oxygen at the moment of enrollment and who had died or were discharged at the time of data collection. Our results can contribute to the general overview regarding the role of these agents in severe COVID-19 pneumonia, suggesting an interesting, even not statistically significant, evidence of the effectiveness of tocilizumab treatment in this disease and sow a seed of reflection about their use in future waves of pandemic. We compared two cohorts of patients selected from those included in the STORM trial [NCT04424992]. The target population was adult with COVID-19 pneumonia diagnosed by nasopharyngeal swab and chest radiography admitted to our hospital before March 20, 2020 and treated with local standard of care. Patients treated with tocilizumab received the experimental treatment $(8 \mathrm{mg} / \mathrm{kg}$ up to a maximum of $800 \mathrm{mg}$ per dose, with an interval of 12 hours for a maximum of two doses) within the TOCIVID-19 trial, ${ }^{10}$ a multicenter single-arm open-label Phase 2 study. Our study was based on an individual matched design done in variable proportion in which each patient treated with tocilizumab on March 21 and 22, 2020 was matched with patients treated with the standard of care according to: age, sex, duration of symptoms from onset to hospitalization, WHO clinical score severity at the day of the first tocilizumab administration (WHO, 2020) and days from admission to tocilizumab administration. Forty-four patients receiving the local standard of care (consisting in hydroxychloroquine $200 \mathrm{mg}$ BID, ceftriaxone $2 \mathrm{~g}$ QD, azithromycin $500 \mathrm{mg}$ QD, acetylcysteine $600 \mathrm{mg}$ BID) were found to match the 31 patients treated with tocilizumab, with a variable ratio ranging from 1 to 3 each. An inferential approach suitable to account for variable matching was adopted. ${ }^{11,12}$

\section{Results and Discussion}

Overall, 65 (87\%) patients were male, median age was 59 (I-III quartiles=57-68) years; 61 (81\%) patients received non-invasive ventilation with PEEP $>0$ (WHO 5 class), the median interval from the onset of symptoms to hospitalization was 7 days and the median interval from hospitalization to tocilizumab was 6 days. The most frequent comorbidity was hypertension in both groups and the standard of care cohort had a higher prevalence of diabetes (30\% vs 6\%, $\mathrm{p}=0.0175)$ (Table 1$)$. With a median followup of 92 days, deaths were 6 and 16 in the tocilizumab and the standard of care group, respectively, with events observed also after 30 days from admission (1 and 2). A significant difference in the mortality of the groups was observed $(p=0.0146)$ : the Kaplan-Meier estimate at 30 days in the experimental group was $16.1 \%(95 \%$ $\mathrm{CI}=7.1-34.5 \%$ ), while the weighted version to account for multiple matching in the control group was $25.8 \%$

Table I Baseline Characteristics of Patients

\begin{tabular}{|c|c|c|c|}
\hline & Tocilizumab $(\mathbf{N}=31)$ & Standard of Care $(N=44)$ & Overall $(\mathbf{N}=75)$ \\
\hline \multicolumn{4}{|l|}{ Characteristics } \\
\hline Age (years*) & $59(54-68)$ & 61 (57-69) & $59(57-68)$ \\
\hline \multicolumn{4}{|l|}{ Sex* } \\
\hline Male & 27 (87\%) & 38 (87\%) & 65 (87\%) \\
\hline Female & $4(13 \%)$ & $6(13 \%)$ & $10(13 \%)$ \\
\hline \multicolumn{4}{|l|}{ Baseline WHO Class* } \\
\hline 4 & I (3\%) & I (2\%) & $2(3 \%)$ \\
\hline 5 & $25(81 \%)$ & $36(82 \%)$ & $61(81 \%)$ \\
\hline 6 & $5(16 \%)$ & $7(16 \%)$ & $12(16 \%)$ \\
\hline Duration of Symptoms* (Days from Onset to Hospitalization) & $7(5-10)$ & $8(6-10)$ & $7(6-10)$ \\
\hline \multicolumn{4}{|l|}{ Comorbidities } \\
\hline Hypertension & 14 (45\%) & $21(49 \%)$ & $35(47 \%)$ \\
\hline Cardiovascular Disease & $4(13 \%)$ & $8(19 \%)$ & 12 (16\%) \\
\hline Diabetes & $2(6 \%)$ & $13(30 \%)$ & 15 (20\%) \\
\hline
\end{tabular}

Notes: Results are reported as number (\%) or median (I-III quartile); *matching factors. 


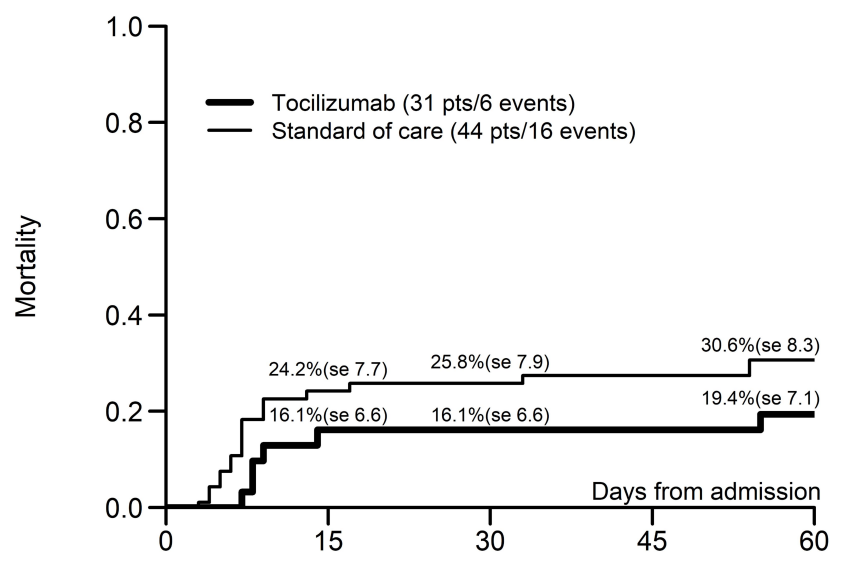

$$
\text { At risk: }
$$

Tocilizumab 31

Standard 44

26

31

26

30

26

29

Figure I Mortality rate in 60 days from hospital admission (standard Kaplan-Meier in the tocilizumab group and weighted Kaplan-Meier in the matched sample). Abbreviation: se, standard error.

(95\% CI=14.6-43.1\%). The 60 days mortality rate were $19.4 \% \quad(95 \% \quad \mathrm{CI}=9.2-38.1) \quad$ and $30.6 \% \quad(95 \%$ $\mathrm{CI}=18.4-48.2 \%$ ), respectively (Figure 1). However, we also performed an analysis with a stratified regression model to adjust for comorbidities, in particular diabetes that was unbalanced between the two groups, and results confirmed an advantage of tocilizumab $(\mathrm{HR}=0.81$, $\mathrm{p}=0.7351$, yet not any more statistically significant.

Thus, with a longer follow-up than previous studies and with a design that guarantees a fair comparison of the two groups at baseline for some relevant factors, we observed, despite the retrospective nature of the study and the small sample size, a reduction in mortality in patients with COVID-19 pneumonia treated with tocilizumab (plus standard of care) compared to standard of care alone, in accordance to the data of the French study by Klopfenstein and colleagues, ${ }^{6}$ and the study by Guaraldi and colleagues. ${ }^{13}$ The recent results of REMAP-CAP confirm the hypothesis of a role of tocilizumab in critically ill patients. ${ }^{14}$ Our data further highlight the need of assessing the effectiveness of tocilizumab in reducing mortality in severe COVID-19 pneumonia.

\section{Ethics Approval and Informed Consent}

The study was conducted according to the Declaration of Helsinki, 2013 and approved by the Istituto Spallanzani and ATS Brianza Ethical Committee. Written or, where it was not possible to collect it due to the critical condition of the patient, verbal informed consent was obtained from all subjects before the study.

\section{Funding}

This research did not receive any specific grant from funding agencies in the public, commercial, or not-forprofit sectors.

\section{Disclosure}

Serena Capici and Luca Sala are co-first authors for this study. Dr Nicola Squillace reports personal fees from ViiV Healthcare, travel grants from Gilead science, outside the submitted work. Professor Paolo Bonfanti reports personal fees from Viiv, Gilead, Merck, Jannsen, and Pfizer, outside the submitted work. The authors report no other conflicts of interest in this work.

\section{References}

1. Zhou F, Yu T, Du R, et al. Clinical course and risk factors for mortality of adult inpatients with COVID-19 in Wuhan, China: a retrospective cohort study. Lancet. 2020;395(10229):1054-1062. doi:10.1016/S0140-6736(20)30566-3

2. Mehta P, McAuley DF, Brown M, et al. COVID-19: consider cytokine storm syndromes and immunosuppression. Lancet. 2020;395 (10229):1033-1034. doi:10.1016/S0140-6736(20)30628-0

3. Quartuccio L, Sonaglia A, McGonagle D, et al. Profiling COVID-19 pneumonia progressing into the cytokine storm syndrome: results from a single Italian Centre study on tocilizumab versus standard of care [published online ahead of print, 2020 May 15]. J Clin Virol. 2020;129:104444. doi:10.1016/j.jcv.2020.104444

4. Campochiaro C, Della-Torre E, Cavalli G, et al. Efficacy and safety of tocilizumab in severe COVID-19 patients: a single-centre retrospective cohort study. Eur J Intern Med. 2020;76:43-49. doi:10.1016/ j.ejim.2020.05.021

5. Colaneri M, Bogliolo L, Valsecchi P, et al. Tocilizumab for treatment of severe COVID-19 patients: preliminary results from SMAtteo COvid19 REgistry (SMACORE). Microorganisms. 2020;8(5):695. doi:10.3390/microorganisms 8050695

6. Klopfenstein T, Zayet S, Lohse A, et al. Tocilizumab therapy reduced intensive care unit admissions and/or mortality in COVID-19 patients. Med Mal Infect. 2020;50(5):397-400. doi:10.1016/j. medmal.2020.05.001

7. Cortegiani A, Ippolito M, Greco M, et al. Rationale and evidence on the use of tocilizumab in COVID-19: a systematic review. Pulmonology. 2021;27(1):52-66. doi:10.1016/j.pulmoe.2020.07.003

8. Stone JH, Frigault MJ, Serling-Boyd NJ, et al. Efficacy of tocilizumab in patients hospitalized with Covid-19. N Engl J Med. 2020;383 (24):2333-2344. doi:10.1056/NEJMoa2028836

9. Salama C, Han J, Yau L, et al. Tocilizumab in patients hospitalized with Covid-19 pneumonia. N Engl J Med. 2021;384(1):20-30. doi:10.1056/NEJMoa2030340

10. Perrone F, Piccirillo MC, Ascierto PA, et al. Tocilizumab for patients with COVID-19 pneumonia. The single-arm TOCIVID-19 prospective trial. $J$ Transl Med. 2020;18(1):405. doi:10.1186/s12967-02002573-9

11. Galimberti S, Sasieni P, Valsecchi MG. A weighted Kaplan-Meier estimator for matched data with application to the comparison of chemotherapy and bone-marrow transplant in leukaemia. Stat Med. 2002;21(24):3847-3864. doi:10.1002/sim.1357 
12. Galimberti S, Valsecchi MG. Multivariate permutation test to compare survival curves for matched data. BMC Med Res Methodol. 2013;13:16. doi:10.1186/1471-2288-13-16

13. Guaraldi G, Meschiari M, Cozzi-Lepri A, et al. Tocilizumab in patients with severe COVID-19: a retrospective cohort study. Lancet Rheumatol. 2020;2(8):e474-e484. doi:10.1016/S26659913(20)30173-9
14. REMAP-CAP Investigators. Interleukin-6 receptor antagonists in critically ill patients with Covid-19. N Engl J Med. 2021. doi:10.1056/NEJMoa2100433

\section{Publish your work in this journal}

Infection and Drug Resistance is an international, peer-reviewed openaccess journal that focuses on the optimal treatment of infection (bacterial, fungal and viral) and the development and institution of preventive strategies to minimize the development and spread of resistance. The journal is specifically concerned with the epidemiology of antibiotic resistance and the mechanisms of resistance development and diffusion in both hospitals and the community. The manuscript management system is completely online and includes a very quick and fair peerreview system, which is all easy to use. Visit http://www.dovepress.com/ testimonials.php to read real quotes from published authors. 